\title{
Patient-reported outcomes and psycho-oncological screening in hematology: a practical example of routine electronic monitoring
}

\author{
Jens Lehmann (D) - Lisa M. Wintner · Monika Sztankay · Wolfgang Willenbacher · Roman Weger • \\ Walpurga Weyrer · Gerhard Rumpold · Bernhard Holzner
}

Received: 24 April 2020 / Accepted: 7 June 2020 / Published online: 3 July 2020

(C) The Author(s) 2020

Summary Patient-reported outcomes (PROs) have gained increasing importance in oncology. PROs can supplement medical treatment with important information about the patient's quality of life (QoL), which is typically assessed using standardized questionnaires. PROs capture the symptomatology and functional impairments as perceived by the patient without further interpretation by another party. In this article, we describe how routinely assessed electronic PROs (ePROs) at the outpatient unit of the Department of Hematology Innsbruck complement the Austrian Myeloma Registry (AMR) and clinical routine. There is a broad body of literature showing that ePRO assessments can supplement patient-physician

J. Lehmann, MSc $(\bowtie) \cdot$ L. M. Wintner · M. Sztankay ·

B. Holzner

University Hospital of Psychiatry II, Medical University of Innsbruck, Anichstraße 35, 6020 Innsbruck, Austria jens.lehmann@i-med.ac.at

\section{M. Wintner}

lisa.wintner@tirol-kliniken.at

\section{Sztankay}

monika.sztankay@tirol-kliniken.at

\section{B. Holzner}

bernhard.holzner@tirol-kliniken.at

M. Sztankay · B. Holzner

Psychiatry II, Innsbruck University Hospital,

Innsbruck, Tirol, Austria

\section{W. Willenbacher $\cdot$ R. Weger}

Internal Medicine V: Hematology and Oncology, Innsbruck

University Hospital, Innsbruck, Austria

W. Willenbacher

wolfgang.willenbacher@tirol-kliniken.at

R. Weger

roman.weger@tirol-kliniken.at contact and help focus communication on clinically relevant issues that matter for the patient. Based on ePRO results, physicians can initiate clinical action such as referring patients to psycho-oncological treatment. Electronic PRO assessments might facilitate communication between healthcare providers among themselves but also between healthcare providers and patients, and make it possible to incorporate the patients' point of view into treatment in a standardized way. The example depicted herein demonstrates how ePRO assessments can be integrated and used in routine monitoring and for psycho-oncological screening.

\footnotetext{
J. Lehmann, MSc $\cdot$ W. Willenbacher $\cdot$ R. Weger

Oncotyrol-Center for Personalized Cancer Medicine, Innsbruck, Austria

W. Weyrer

Comprehensive Cancer Center Innsbruck, Innsbruck University Hospital, Innsbruck, Austria walpurga.weyrer@tirol-kliniken.at

G. Rumpold

University Clinic of Medical Psychology, Medical University of Innsbruck, Innsbruck, Austria gerhard.rumpold@tirol-kliniken.at
} 
Keywords Oncology · ePRO · Quality of life · Multiple myeloma $\cdot$ Chronic lymphocytic leukemia

\section{Introduction}

In recent years, treatments for hematological cancer have achieved prolonged survival and have shifted the patients' quality of life (QoL) more and more into focus [1-3]. Among other self-reported health concepts, QoL can be assigned to the umbrella term of patient-reported outcomes (PROs), which in turn can be defined as all health outcomes directly reported by the patient without any interpretation by a second party. PROs are typically assessed using standardized questionnaires measuring patients' symptoms and functioning (physical and psychosocial domains). PRO data can help patients and physicians decide which treatment options to pursue and allow meaningful insight in the patient's health status over the whole course of the disease. Such standardized integration of the patient perspective can supplement the medical assessment of the patient's state of health. Studies have shown that healthcare professionals (HCPs) often undervalue symptoms and functional impairments in patients' QoL $[4,5]$. PROs can provide added value for the patient-physician relationship and may even increase survival time as initial studies have shown [6, 7].

\section{How are PROs assessed?}

PRO assessments are typically used in clinical studies or in routine care monitoring. On a basic level, PROs on QoL are either broad instruments applicable to a general population, or specific instruments validated for certain groups (e.g., disease groups like cancer). Usage of generic PRO tools like the EQ$5 \mathrm{D}$ or the Short Form Health Survey (SF-36) permits a comparison across different disease groups. However, those questionnaires do not cover diseasespecific domains and symptoms that may be relevant to patients. In most cases, using a cancer-specific measurement is advisable, as those more precisely measure issues relevant to oncological patients. One of the most widely used PRO measures is the European Organisation for Research and Treatment of Cancer Quality of Life Questionnaire (EORTC QLQC30) [8-10], developed by the EORTC Quality of Life Group, which can be supplemented using diseasespecific modules for different types of cancer. Other cancer-specific PRO tools are the PROMIS-Cancer measures by the National Cancer Institute (NCI) or the Functional Assessment of Cancer Therapy - General (FACT-G). Depending on the focus of the assessments, the PRO measure should be selected carefully $[11,12]$. Additional specific questionnaires can be used to assess particular domains of interest such as the need or indication for psycho-oncological treat- ment, e.g., Distress Thermometer [13] or Hornheider Screening Instrument (HSI) [14].

While in clinical studies the results of PRO measures are often analyzed after conducting the study, requirements for PRO usage in clinical routine are different. Research has shown that the integration of PRO results into the clinical workflow benefits from instant scoring and comprehensive PRO result presentation [15, 16]. This can be accomplished with electronic patient-reported outcome (ePRO) data collection. Using PCs, tablet-PCs or smartphone devices, patients can report on PRO measures. Directly after completion, HCPs can review the results and tailor the clinical encounter to the patient's responses. Compared to paper-pencil data collection, ePRO data collection has been shown to improve data integrity and reduce missing data in clinical trials [17] while offering the same validity [18].

\section{Why assess PROs in oncological care?}

Assessing PROs offers a variety of benefits in the clinical setting. PROs can systematically assess relevant symptoms and side effects that may be relevant to treatment. The PRO results, especially when collected electronically, can help HCPs gain a quick and comprehensive impression of the patients' perceived health. Review of the results may lead to clinical exploration of the data or initiate clinical action. For example, for the EORTC QLQ-C30, thresholds for clinical importance are available indicating a high possibility for clinically important problems in a patient's QoL [19]. These thresholds can be used for symptom screening in clinical practice. Well-validated and established PRO tools like the EORT QLQC30, combined with interpretation guidelines such as normative data or thresholds for clinical importance, allow the comprehensive and systematic assessment and interpretation of patients' QoL. Due to the broad assessment focus of standardized questionnaires, different sensitive domains (like fatigue, sexuality) are addressed which are otherwise less likely to be picked up during consultation [20-22]. At the same time, a wider variety of topics can be covered in the consultations if PRO results are used because PROs can cover a broad range of QoL domains [23, 24]. Another welcome effect is that PRO results can support focused dialogue between HCPs and patients, as they give an indication on which topics or QoL domains merit in-depth discussion [20]. Even though more topics are picked up and discussed, the time spent with the patient during consultation remains the same [20, 24]. Focusing patient-relevant issues and evaluating patient priorities can support shared-decision making in therapy which in turn can increase treatment satisfaction and adherence in patients [24-26].

In the last few years, the first RCT studies were able to show concrete survival benefits of PRO usage in the oncological setting. Basch et al. [6] report on 
advanced lung cancer patients using a weekly webbased symptom monitoring during routine care. In the usual care group, no ePRO monitoring was carried out. If a patient in the ePRO group deteriorated or showed specific symptoms, an HCP was notified and could update the treatment accordingly (e.g., schedule additional imaging). Patients in the ePRO monitoring group showed a median prolonged survival of 5 months compared to patients in standard care. Similar results were reported by Denis et al., recruiting advanced nonprogressive stage IIA (TXN1) to IV lung cancer patients at five French centers [7]. In their study, median survival was 22.5 months (ePRO group) versus 13.5 months (standard of care). The authors conclude that ePRO integration enabled more adequate and timelier provision of care and therefore prolonged survival. Early detection of and adequate response to side effects are known factors to reduce unplanned hospital visits and increase patients' therapy adherence [27]. Furthermore, patients in the study by Denis et al. also tolerated longer chemotherapy than patients in usual care, which could be another contributing factor.

\section{ePRO data collection in the outpatient unit of the Department of Hematology Innsbruck}

Since 2016, the Department of Hematology Innsbruck has been conducting standardized QoL assessments in cooperation with the Austrian Myeloma Registry (AMR, https://www.myeloma-registry.com) at the outpatient unit. The AMR incorporates clinical data of patients with multiple myeloma (MM) in multiple representative centers in Austria. In Innsbruck, the clinical data are complemented with ePRO assessments. So far, over 250 patients with MM have participated in the ePRO assessments in Innsbruck. Due to the successful integration and the perceived benefits for MM patients, another patient group, patients with chronic lymphatic leukemia (CLL), was added to the standard clinical monitoring in 2017. Since then, roughly 200 patients with CLL have participated. In total, more than 3200 ePRO assessments have been completed (January 2020). The implementation procedure and feasibility of the ePRO data assessments for integration into the AMR has been published elsewhere [28].

Patients with MM are included into the registry and routine QoL assessments are carried out by an ePRO facilitator (HCP responsible for the assessments). The EORTC QLQ-C30 [29] and the myeloma-specific module EORTC QLQ-MY20 [30] are used for patients with MM. For patients with CLL, the data are only utilized for routine clinical monitoring using the EORTC QLQ-C30 together with the EORTC QLQ-CLL17 [31]. All EORTC questionnaires are available in multiple languages, which allows non-native German speakers to choose their preferred language for completion. The assessments are carried out on a tablet at the outpatient unit or using a web-based patient portal which patients can access from home. This ePRO approach is realized using the Computer-based Health Evaluation System (CHES, [32]) which captures the PRO data for the registry and simultaneously provides instant graphical representation of the patients' results. Healthcare practitioners can use the CHES to get a quick and informative overview of their patients' perceived QoL in the last week. Patients' results can be compared to previous assessments and/or to normative data from other cancer patients. This allows the tracking and longitudinal monitoring of patients QoL over treatment trajectory. The EORTC has recently published a guideline on ePRO implementation in research and practice [33]. The Graphical User Interface for the Department of Hematology was crafted in accordance with those guidelines (an exemplary representation of patients' results is shown in Fig. 1).

\section{Psycho-oncological screening}

A cancer diagnosis is often physically and emotionally burdensome for patients and can result in high psychosocial and emotional distress for the individual and/or family [34]. According to the literature, $20-50 \%$ of cancer patients are emotionally distressed $[35,36]$ or have psychiatric comorbidities during therapy [37]. Consequently, cancer treatment should be supplemented with adequate psychosocial support such as psycho-oncological treatment which can increase patients' QoL and decrease distress [38, 39]. For HCPs, it can be challenging to identify patients in need of support and referral to psycho-oncological services as many patients do not proactively report distress or seek help, and HCPs might lack specific training to identify distressed patients [40, 41]. Although cancer-specific questionnaires usually assess emotional functioning or distress, this does not suffice for the identification of patients in need of psychooncological support and treatment [42]. Therefore, treatment guidelines suggest the use of a routine psycho-oncological screening tool [43]. In August 2019, the Hornheider Screening Instrument (HSI) [14] was added to the ePRO routine monitoring at our unit. The original version of the HSI contains seven items assessing emotional strain, unmet information needs and disease burden in the family. A cut-off indicates patients who would likely benefit from psycho-oncological treatment. For the screening of psychooncological treatment needs at the Department of Hematology Innsbruck, the HSI is supplemented with five additional items on episodes of depressive mood or anxiety, previous psychological or psychiatric treatment, and patients' personal wish to talk to a psychooncologist. This results in a total of 12 items which has been shown to be feasible for screening purposes [44]. To keep response burden low, patients complete the HSI screening in 3-month intervals. In CHES, the HSI cut-off is linked to a graphical indicator (a blue 


\begin{tabular}{|c|c|c|c|c|c|c|c|c|c|c|c|c|c|}
\hline \multicolumn{2}{|c|}{ Firstname Lastname $\vee$} & \multicolumn{6}{|l|}{+} & Search & $x$ & (2) All indications & \multirow[b]{2}{*}{ Flag } & \multirow[b]{2}{*}{ Delta } & \multirow[b]{2}{*}{ PO } \\
\hline \multirow[t]{7}{*}{ Survey } & Monitoring & Info & Last Name & First Name & Date of Birth & Pat. ID & Diagnosis & Assessments & Last & Next & & & \\
\hline & Klinik & & & & & & C91.1-Chronisch.. & 2 & $16 / 03 / 2020$ & & & $\rightarrow$ & \\
\hline & Klinik & & & & & & C91.1-Chronisch.. & 4 & $17 / 03 / 2020$ & & & $\rightarrow$ & \\
\hline & Portal & & & & & & C90 - Multiples M... & 12 & $13 / 03 / 2020$ & & & $\rightarrow$ & ! \\
\hline & Klinik & & & & & & C90 - Multiples M... & 1 & $23 / 03 / 2020$ & & & & \\
\hline & Portal & & & & & & C91.1-Chronisch.. & 4 & $06 / 03 / 2020$ & & & $\rightarrow$ & \\
\hline & Portal & 12 & Lastname & Firstname & $02 / 06 / 1950$ & Pat-ID-here & C90 - Multiples M... & 2 & $27 / 02 / 2020$ & $23 / 03 / 2020$ & & & ! \\
\hline
\end{tabular}

a

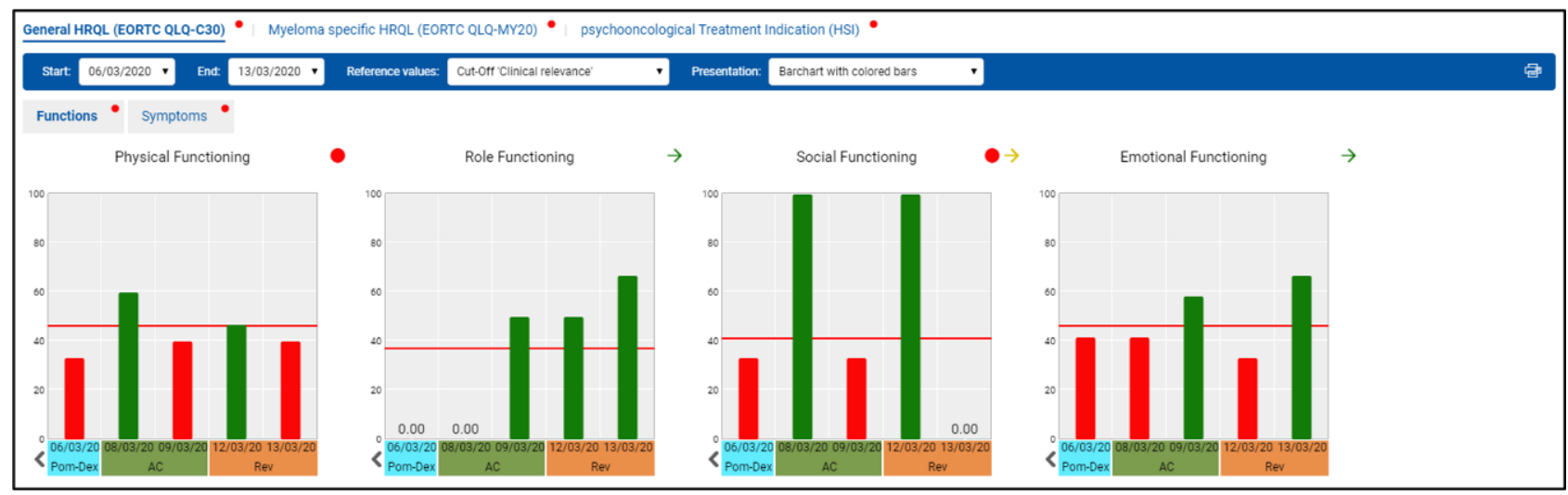

b

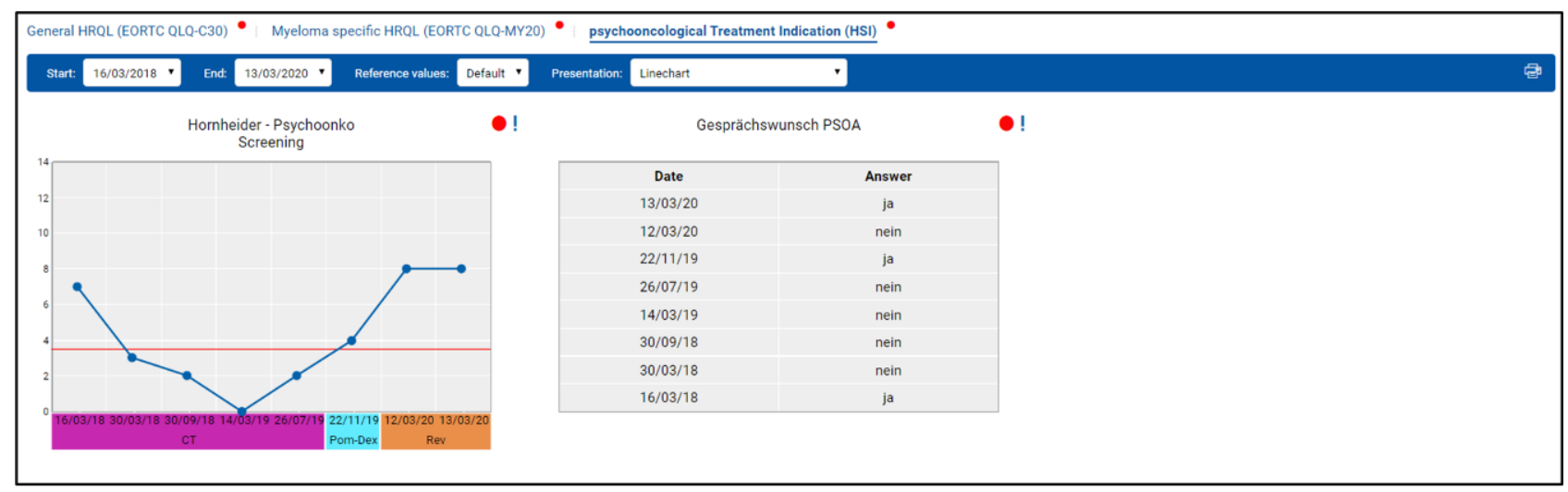

C

Fig. 1 Exemplary PRO results. Different options for displaying PRO results are available: a the patient list with example patients, b longitudinal questionnaire results for an example patient's EORTC QLQ-C30, c longitudinal questionnaire results for the HSI showing the clinical cut-off and the patients

exclamation mark) in the patient overview, which makes it easy for HCPs to identify patients who might benefit from psycho-oncological treatment. The exclamation mark is displayed when patients exceed the HSI cut-off (regardless of whether they wish to see a psycho-oncologist) or when they express the wish to see a psycho-oncologist (regardless of whether they exceed the cut-off). Fig. 2 (adapted from [45]) displays the possible outcomes and resulting actions taken by the staff depending on the HSI results.

Between implementation of the screening in $\mathrm{Au}$ gust 2019 and January 2020, 91 patients completed at least one HSI screening. Of those, 40 (44\%) ex- wish for psycho-oncological treatment. PRO patient-related outcome. EORTC QLQ-C30 European Organisation for Research and Treatment of Cancer Quality of Life Questionnaire, HSI Hornheider Screening Instrument

ceeded the cut-off during the first screening but only 5 (5\%) wished to talk to a psycho-oncologist. This gap between experienced distress and expressed wish for psycho-oncological support is known from other studies, although normally less prominent (e.g., [46-48]). Proposed reasons for few patients expressing the wish to see a psycho-oncologist are the fear of social stigma, a lack of knowledge about psycho-oncology, a preference for self-help, and the belief that their own distress is not severe enough to merit intervention [46, 49]. 


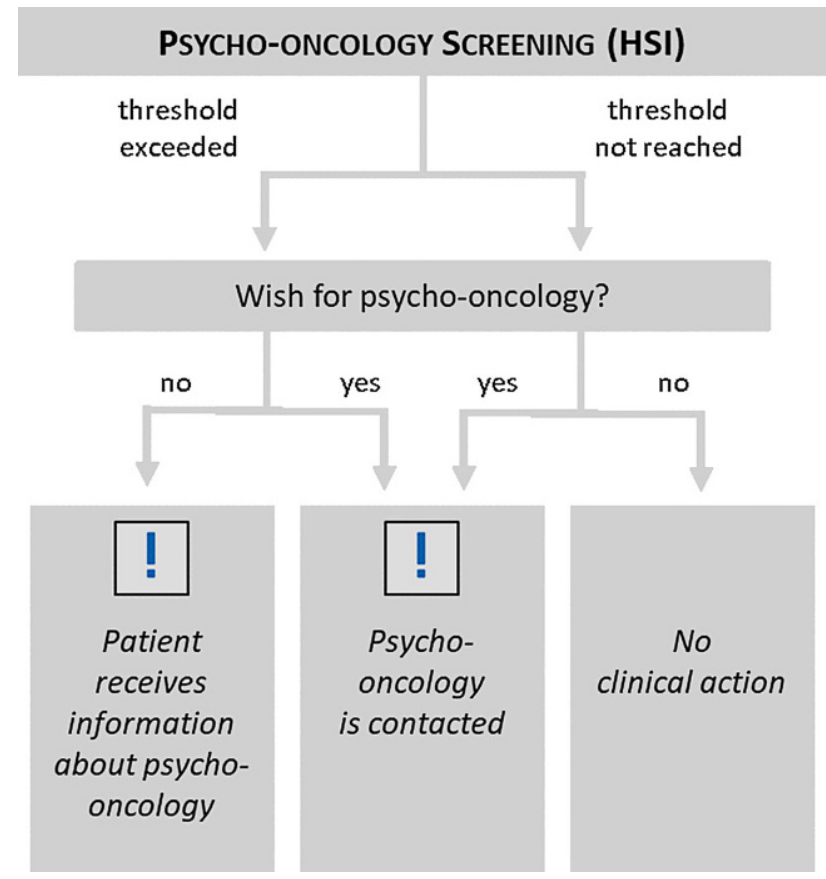

Fig. 2 Pathways of clinical action due to psycho-oncological screening. Depending on the screening outcome of the Hornheider Screening Instrument (HSI), different clinical actions are executed. The blue exclamation mark is shown as an indicator of necessary clinical action for healthcare professionals. Adapted from Schäffeler et al. [45]

\section{ePRO from the patients' perspective}

The patient perspective on the PRO assessments is a critical factor for any implementation. Research suggests that how patients experience the assessments is connected to their compliance [50] and satisfaction with the PRO usage [51]. At our outpatient unit, patients with MM and CLL are approached in the clinic by the ePRO facilitator. They are asked to participate in the monitoring program and, in case of a MM diagnosis, to consent to data usage by the AMR. After providing informed consent, the patient is presented further information about the goals and procedure of the monitoring. Patients then fill in the questionnaires for the first time on a tablet computer in a designated room. Patients can choose their preferred or native language, which reduces misunderstandings and includes foreign-language speakers. Due to the multilingual assessments, ePROs can help bridge language-based communication gaps between patients and physicians as they provide an extensive assessment in various languages. During questionnaire completion, the ePRO facilitator is present and can assist patients who require support with the assessment. The assessment is usually carried out between the blood sampling and the appointment with the doctor. This ensures that ePRO results can be reviewed by the doctor before and during the consultation. After the first inclusion into the routine monitoring, regular assessments are carried out at each subsequent visit at the outpatient unit. Assessment intervals differ with appointment frequency and can range anywhere between 2 weeks and 12 months.

Patients who are eligible to participate in an electronic PRO home monitoring (at least some internet usage, and no overt cognitive impairment) are introduced to our patient portal. Approval rates for the portal are high: most eligible patients agree to use the portal (79 of $88 ; 90 \%)$. Aside from questionnaire completion, the patient portal offers additional features for the patients. It provides reliable disease-specific information composed by the physicians and content which is dependent on patients' questionnaire results. Self-management tools are dynamically displayed for QoL domains if a threshold for clinical importance is reached [19]. The self-management tools consist of advice and instructions on how to handle diseaseand treatment-related symptom burden (e.g. breathing exercise, dietary information), or contact information to relevant counseling sources such as psychooncology. Patients are recommended to view the selfhelp tools for domains in which they reached the predefined threshold. Moreover, patients can view their own results and compare them to reference data from other patients, a wish frequently reported by cancer patients [52].

\section{ePRO from the physicians' perspective}

Physicians entering the program for the first time are also introduced to the routine monitoring by the ePRO facilitator and are provided their own login data for the CHES system. Their account allows them to log into the CHES platform using just an internet browser at any time. Evaluation of the feasibility in our unit shows that the effort and burden of the ePRO assessments for physicians is low [28]. Typically, physicians are advised to review their patient's PRO results right before or during the consultation. They can choose just how much specific information they want to extract from the ePRO assessments: (level 1) inspect just a pie chart summarizing the results of all subscales of the three questionnaires and an indicator of change from the last assessment, (level 2) inspect the results for all subscales split by functions and symptoms, or (level 3) to check the specific answers a patient gave that led to the results at hand. This way physicians can adapt the amount of specific information to their needs. For instance, if the patients reported QoL did not deteriorate, it might be sufficient to just check the summarizing pie chart (Fig. 3). Otherwise, if the patient shows deterioration in some domains, the doctor can inspect the respective items and receive detailed information.

Routinely assessed PRO data can support HCPs in more easily adapting a patient-centered approach. Thresholds for clinical importance are used to identify QoL domains that might be clinically relevant [19]. If the threshold is passed for a subscale, it is likely that 
High

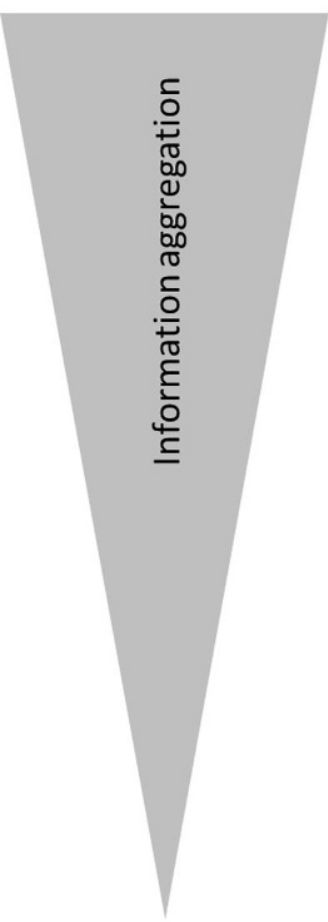

Low
Level 1
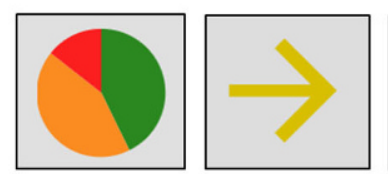

Level 2

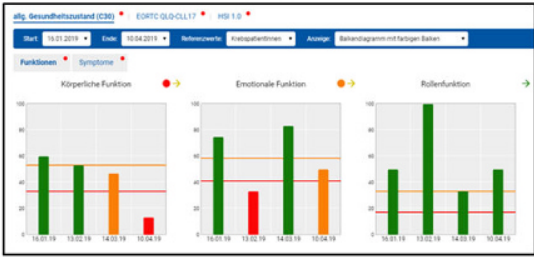

Level 3

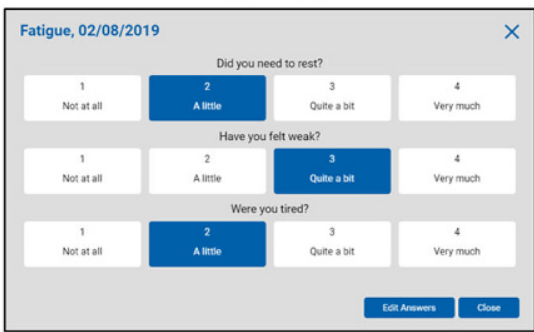

ranum cones
Fig. 3 Levels of information depth and aggregation in the software. Information is most condensed on level 1: In the pie chart, arrow (delta indicator of change between the last assessments) and psycho-oncology flag (exclamation mark shown for psycho-oncological treatment indication) all questionnaires and subscales are aggregated. Subsequently, this level conveys the least specific information. Level 2: Health-

the patient experiences clinically important problems in this domain. Physicians are advised to discuss those domains with the patient. The blue exclamation mark as an indication of a possible psychooncological treatment indication helps in the early recognition of patients who might benefit from further counselling and triggers adequate clinical action. Moreover, as the psycho-oncologists have access to the QoL data, they can obtain additional information on the health state of the patient from the PRO results before even meeting him or her.

\section{Conclusion and future perspective}

The outpatient unit of the Department of Hematology in Innsbruck successfully implemented the collection of ePRO (electronic patient-rated outcome) data on a regular basis to supplement the AMR (Austrian Myeloma Registry). This routine ePRO assessment should not stop at being a mere data collection, but gradually progress to enrich clinical care and research. Herein, we review the possible benefits of ePRO assessments in hematology and how routine ePRO screening can be used for psycho-oncological triage. In order to underpin the beneficial nature of
Low

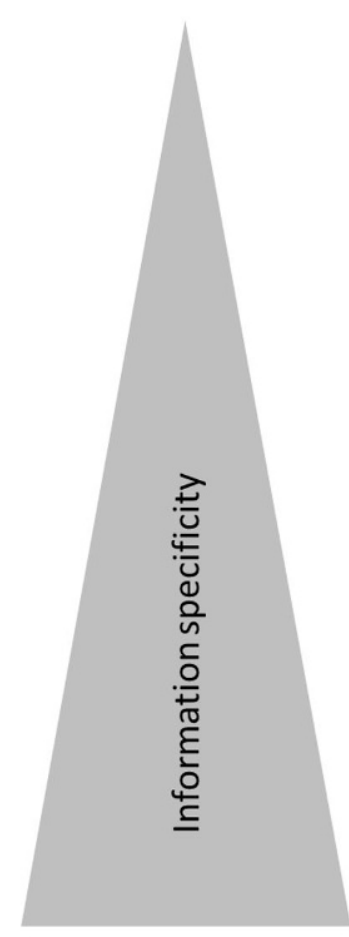

High

care practitioners can choose to explore the ePRO data in depth, by viewing the questionnaires' subscales and their trajectories. On this level, information is more specific. Level 3 (highest information specificity): If even more detailed information is needed, the answers to items of a specific subscale can be viewed. ePRO electronic patient-reported outcome

the structured use of ePRO data, follow-up projects will evaluate and analyze the routine assessment and associated care pathways like the triage of psychooncology treatment. A detailed analysis of clinical action initiated by healthcare professionals based on the psycho-oncology screening results may be used to gauge the benefit in treatment allocation provided by the screening. Another research focus on the use of the patient portal and the patients' opinion of the patient portal will help to identify both successful and useful functionalities as well as areas for improvement. To reinforce patients to provide their ePRO data upfront their appointment at the hospital, the use of the patient portal should bear additional incentives like adequate and feasible self-management tools or selected up-to-date medical information.

\section{Take-home message}

- Systematic patient-reported outcome (PRO) assessments in hematological patients are a sensible addition to standardized treatment monitoring.

- Patient-reported outcomes can enrich the patientphysician contact and help focus on clinically relevant issues that matter for the patient. 
- This example of electronic PRO monitoring at the outpatient unit of the Department of Hematology Innsbruck shows that PROs can be a part of routine medical assessment.

- We demonstrate how PROs can be used for the screening of psycho-oncological treatment indication and referral.

Funding Open access funding provided by University of Innsbruck and Medical University of Innsbruck.

Conflict of interest B. Holzner and G. Rumpold have intellectual property rights of the software tool CHES. J. Lehmann, L.M. Wintner, M. Sztankay, W. Willenbacher, R. Weger, and W. Weyrer declare that they have no competing interests.

Open Access This article is licensed under a Creative Commons Attribution 4.0 International License, which permits use, sharing, adaptation, distribution and reproduction in any medium or format, as long as you give appropriate credit to the original author(s) and the source, provide a link to the Creative Commons licence, and indicate if changes were made. The images or other third party material in this article are included in the article's Creative Commons licence, unless indicated otherwise in a credit line to the material. If material is not included in the article's Creative Commons licence and your intended use is not permitted by statutory regulation or exceeds the permitted use, you will need to obtain permission directly from the copyright holder. To view a copy of this licence, visit http://creativecommons.org/licenses/by/4.0/.

\section{References}

1. Mohty M, Terpos E, Mateos MV, Cavo M, Lejniece S, Beksac M, et al. Multiple myeloma treatment in realworld clinical practice: results of a prospective, multinational, noninterventional study. Clin Lymphoma Myeloma Leuk. 2018;18(10):e401-e19. https://doi.org/10.1016/j. clml.2018.06.018.

2. Willenbacher E, Weger R, Rochau U, Siebert U, Willenbacher W. Real-world use of 3rd line therapy for multiple myeloma in Austria: an Austrian myeloma registry (AMR) analysis of the therapeuticlandscape and clinical outcomes prior to the use of next generation myeloma therapeutics. PLoS ONE. 2016;11(3):e147381. https://doi.org/10.1371/ journal.pone.0147381.

3. Kumar SK, Dispenzieri A, Lacy MQ, Gertz MA, Buadi FK, Pandey S, et al. Continued improvement in survival in multiple myeloma: changes in early mortality and outcomes in older patients. Leukemia. 2014;28(5):1122-8. https://doi. org/10.1038/leu.2013.313.

4. Barata A, Martino R, Gich I, Garcia-Cadenas I, Abella E, Barba P, et al. Do patients and physicians agree when they assess quality of life? Biol Blood Marrow Transplant. 2017;23(6):1005-10. https://doi.org/10.1016/j.bbmt.2017. 03.015 .

5. Schuurhuizen C, Marino P, Braamse AMJ, Buffart LM, Joly F, Fizazi K, et al. Impact of patient- and clinician-reported cumulative toxicity on quality oflifein patients with metastatic castration-naive prostate cancer. J Natl Compr Canc Netw. 2018;16(12):1481-8. https://doi.org/10.6004/jnccn.2018. 7069.

6. Basch E, Barbera L, Kerrigan CL, Velikova G. Implementation of patient-reported outcomes in routine medical care. Am Soc Clin OncolEduc Book. 2018;38:122-34. https://doi. org/10.1200/EDBK_200383.
7. Denis F, Basch E, Septans AL, Bennouna J, Urban T, Dueck AC, et al. Two-year survival comparing webbased symptom monitoring vs routine surveillance following treatment for lung cancer. JAMA. 2019;321(3):306-7. https://doi.org/10.1001/jama.2018.18085.

8. Smith AB, Cocks K, Parry D, Taylor M. Reporting of healthrelated quality of life (HRQOL) data in oncology trials: a comparison of the European organization for research and treatment of cancer quality oflife (EORTCQLQ-C30) and the functional assessment of cancer therapy-general (FACT-G). Qual Life Res. 2014;23(3):971-6. https://doi.org/10.1007/ s11136-013-0534-2.

9. Howell D, Molloy S, Wilkinson K, Green E, Orchard K, Wang K, et al. Patient-reported outcomes in routine cancer clinical practice: a scoping review of use, impact on health outcomes, and implementation factors. Ann Oncol. 2015;26(9):1846-58. https://doi.org/10.1093/annonc/ mdv181.

10. GnanasakthyA, BarrettA, Evans E, D'Alessio D, Romano CD. A review of patient-reported outcomes labeling for oncology drugs approved by the FDA and the EMA (2012-2016). Value Health. 2019;22(2):203-9. https://doi.org/10.1016/j. jval.2018.09.2842.

11. Luckett T, King MT, Butow PN, Oguchi M, Rankin N, Price MA, et al. Choosing between the EORTC QLQC30 and FACT-G for measuring health-related quality of life in cancer clinical research: issues, evidence and recommendations. Ann Oncol. 2011;22(10):2179-90. https://doi. org/10.1093/annonc/mdq721.

12. Wintner LM, Sztankay M, Aaronson N, Bottomley A, Giesinger JM, Groenvold M, et al. The use of EORTC measures in daily clinical practice-a synopsis of a newly developed manual. Eur J Cancer. 2016;68:73-81. https:// doi.org/10.1016/j.ejca.2016.08.024.

13. Zwahlen D, Hagenbuch N, Jenewein J, Carley MI, Buchi S. Adopting a family approach to theory and practice: measuring distress in cancer patient-partner dyads with the distress thermometer. Psychooncology. 2011;20(4):394-403. https://doi.org/10.1002/pon.1744.

14. Strittmatter G, Gerhards M. Hornheider Screening Instrument. In: Herschbach P, Weis J, editors. Screeningverfahren in der Psychoonkologie. Testinstrumente zur Identifikation betreuungsbedürftiger Krebspatienten. Berlin: Deutsche Krebsgesellschafte. V;2008.

15. Jensen RE, Snyder CF, Abernethy AP, Basch E, Potosky AL, Roberts AC, et al. Review of electronic patient-reported outcomes systems used in cancer clinical care. J Oncol Pract. 2014;10(4):e215-22. https://doi.org/10.1200/jop. 2013.001067.

16. de Beurs E, den Hollander-Gijsman ME, van Rood YR, van der Wee NJA, Giltay EJ, van Noorden MS, et al. Routine outcome monitoring in the Netherlands: practical experiences with a web-based strategy for the assessment of treatment outcome in clinical practice. Clin Psychol Psychother. 2011;18(1):1-12. https://doi.org/10.1002/cpp.696.

17. Schick-Makaroff K, Molzahn A. Strategies to use tablet computers for collection of electronic patient-reported outcomes. Health Qual Life Outcomes. 2015;13:2. https:// doi.org/10.1186/s12955-014-0205-1.

18. Gwaltney CJ, Shields AL, Shiffman S. Equivalence of electronic and paper-and-pencil administration of patientreported outcome measures: a meta-analytic review. Value Health. 2008;11(2):322-33. https://doi.org/10.1111/j. 1524-4733.2007.00231.x.

19. Giesinger JM, Loth FLC, Aaronson NK, Arraras JI, Caocci G, Efficace F, et al. Thresholds for clinical importance were established to improve interpretation of the EORTC QLQ- 
C30 in clinical practice and research. JClin Epidemiol. 2019; https://doi.org/10.1016/j.jclinepi.2019.10.003.

20. Detmar SB, Muller MJ, Schornagel JH, Wever LD, Aaronson NK. Health-related quality-of-life assessments and patient-physician communication: a randomized controlled trial. JAMA. 2002;288(23):3027-34. https://doi.org/10. 1001/jama.288.23.3027.

21. Hilarius DL, Kloeg PH, Gundy CM, Aaronson NK. Use of health-related quality-of-life assessments in daily clinical oncology nursing practice: a community hospital-based intervention study. Cancer. 2008;113(3):628-37. https:// doi.org/10.1002/ cncr.23623.

22. Taenzer P, Bultz BD, Carlson LE, Speca M, DeGagne T, Olson $\mathrm{K}$, etal. Impact of computerized quality of life screening on physician behaviour and patient satisfaction in lung cancer outpatients. Psychooncology. 2000;9(3):203-13.

23. Frost MH, Bonomi AE, Cappelleri JC, Schunemann HJ, Moynihan TJ, Aaronson NK. Applying quality-of-life data formally and systematically into clinical practice. Mayo Clin Proc. 2007;82(10):1214-28. https://doi.org/10.4065/ 82.10.1214.

24. Velikova G, BoothL, SmithAB, Brown PM, LynchP, BrownJM, et al. Measuring quality of life in routine oncology practice improves communication and patient well-being: a randomized controlled trial. J Clin Oncol. 2004;22(4):714-24. https://doi.org/10.1200/jco.2004.06.078.

25. Kane HL, Halpern MT, Squiers LB, Treiman KA, McCormack LA. Implementing and evaluating shared decision making in oncology practice. CA Cancer J Clin. 2014;64(6):377-88.

26. Velikova G, Keding A, Harley C, Cocks K, Booth L, Smith AB, et al. Patients report improvements in continuity of care when quality of life assessments are used routinely in oncology practice: secondary outcomes of a randomised controlled trial. Eur J Cancer. 2010;46(13):2381-8.

27. Mooney K, Berry DL, Whisenant M, Sjoberg D. Improving cancer care through the patient experience: how to use patient-reported outcomes in clinical practice. Am Soc Clin Oncol Educ Book. 2017;37:695-704. https://doi.org/10. 14694/edbk_175418.

28. Sztankay M, Neppl L, Wintner LM, Loth F, Willenbacher W, Weger R, et al. Complementing clinical cancer registry data with patient-reported outcomes: a feasibility study on routine electronic patient-reported outcome assessment for the Austrian myelome registry. Eur J Cancer Care. 2019; https://doi.org/10.1111/ecc.13154.

29. Aaronson NK, Ahmedzai S, Bergman B, Bullinger M, Cull A, Duez NJ, et al. The European organization for research and treatment of cancer QLQ-C30: a quality-of-life instrument for use in international clinical trials in oncology. J Natl Cancer Inst. 1993;85(5):365-76. https://doi.org/10.1093/ jnci/85.5.365.

30. Cocks K, Cohen D, Wisløff F, Sezer O, Lee S, Hippe E, et al. An international field study of the reliability and validity of a disease-specific questionnaire module (the QLQ-MY20) in assessing the quality of life of patients with multiple myeloma. Eur J Cancer. 2007;43(11):1670-8. https://doi. org/10.1016/j.ejca.2007.04.022.

31. van dePoll-Franse L, Oerlemans S, BredartA, Kyriakou C, Sztankay M, Pallua S, et al. International development of four EORTCdisease-specific quality oflifequestionnaires forpatients with Hodgkin lymphoma, high- and low-grade nonHodgkin Lymphoma and chronic lymphocytic leukaemia. Qual Life Res. 2018;27(2):333-45. https://doi.org/10.1007/ s11136-017-1718-y.

32. Holzner B, Giesinger JM, Pinggera J, Zugal S, Schopf F, Oberguggenberger AS, et al. The computer-based health evaluation software (CHES): a software for electronic patient-reported outcome monitoring. BMC Med Inform Decis Mak. 2012;12:126. https://doi.org/10.1186/14726947-12-126.

33. Kuliś D, Holzner B, Koller M, Ruyskart P, Itani A, Williams P, et al. Guidance on the implementation and management of EORTC quality of life instruments in electronic applications. 2018.

34. Lang-Rollin I, Berberich G. Psycho-oncology. Dialogues Clin Neurosci. 2018;20(1):13-22.

35. Holland JC, Andersen B, Breitbart WS, Buchmann LO, Compas B, Deshields TL, et al. Distress management. J Natl Compr Canc Netw. 2013;11(2):190-209. https:// doi.org/10. 6004/jnccn.2013.0027.

36. Mehnert A, Hartung TJ, Friedrich M, Vehling S, Brähler E, Härter M, et al. One in two cancer patients is significantly distressed: prevalence and indicators of distress. Psychooncology. 2018;27(1):75-82. https://doi.org/10.1002/ pon. 4464 .

37. Mitchell AJ, Chan M, Bhatti H, Halton M, Grassi L, Johansen C, et al. Prevalence of depression, anxiety, and adjustment disorder in oncological, haematological, and palliative-care settings: a meta-analysis of 94 interviewbased studies. LancetOncol. 2011;12(2):160-74.

38. Faller H, Schuler M, Richard M, Heckl U, Weis J, Küffner R. Effects of psycho-oncologic interventions on emotional distress and quality of life in adult patients with cancer: systematic review and meta-analysis. J Clin Oncol. 2013;31(6):782-93. https://doi.org/10.1200/JCO.2011.40. 8922.

39. Hart SL, Hoyt MA, Diefenbach M, Anderson DR, Kilbourn KM, Craft LL, et al. Meta-analysis of efficacy of interventions for elevated depressive symptoms in adults diagnosed with cancer. J Natl Cancer Inst. 2012;104(13):990-1004. https://doi.org/10.1093/jnci/ djs256.

40. Keller M, Sommerfeldt S, Fischer C, Knight L, Riesbeck M, Löwe B, et al. Recognition of distress and psychiatric morbidity in cancer patients: a multi-method approach. Ann Oncol. 2004;15(8):1243-9. https://doi.org/10.1093/ annonc/mdh318.

41. Fallowfield L, Ratcliffe D, Jenkins V, Saul J. Psychiatric morbidity and its recognition by doctors in patients with cancer. Br J Cancer. 2001;84(8):1011-5. https://doi.org/10. 1054/bjoc.2001.1724.

42. Götz A, Kröner A, Jenewein J, Spirig R. Evaluation of the adherence of distress screening with the distress thermometer in cancer patients 4 years after implementation. Support Care Cancer. 2019;27(8):2799-807. https://doi.org/10. 1007/s00520-018-4579-1.

43. Deutsche Krebsgesellschaft (DKG). Leitlinienprogramm Onkologie: Psychoonkologische Diagnostik, Beratung und Behandlung von erwachsenen Krebspatienten. 2014.

44. Loth FL, Meraner V, Holzner B, Singer S, Virgolini I, Gamper EM. Following patient pathways to psycho-oncological treatment: identification of treatment needs by clinical staff and electronic screening. Psychooncology. 2018;27(4):1312-9. https://doi.org/10.1002/pon.4675.

45. Schaeffeler N, Sedelmaier J, Möhrer H, Ziser K, Ringwald J, Wickert M, et al. Patient's autonomy and information in psycho-oncology: computer based distress screeningfor an interactive treatment planning (ePOS-react). Psychother Psychosom Med Psychol. 2017;67(7):296-303. https://doi. org/10.1055/s-0043-113438.

46. de Zwaan M, Mösch P, Sinzinger H, Stresing K, Oberhof P, Kohl C, et al. The association between the need for psychosocial support, patients' desire for psychosocial 
support and received psychosocial interventions in cancer patients. Neuropsychiatr. 2012;26(4):152-8. https://doi. org/10.1007/s40211-012-0035-5.

47. van Scheppingen C, Schroevers MJ, Smink A, van der Linden YM, Mul VE, LangendijkJA, et al. Does screening for distress efficientlyuncover meetableunmetneedsincancer patients? Psychooncology. 2011;20(6):655-63. https:// doi. org/10.1002/pon.1939.

48. Schaeffeler N, Pfeiffer K, Ringwald J, Brucker S, Wallwiener M, Zipfel S, et al. Assessing the need for psychooncological support: screening instruments in combination with patients' subjective evaluation may define psychooncological pathways. Psychooncology. 2015;24(12):1784-91. https://doi.org/10.1002/pon.3855.

49. Clover KA, Mitchell AJ, Britton B, Carter G. Why do oncology outpatients who report emotional distress decline help? Psychooncology. 2015;24(7):812-8. https://doi.org/10. 1002/pon.3729.

50. Ross J, Holzbaur E, WadeM, RothrockT. Patient perspective: pro compliance and effective reminder strategies. Value Health. 2014;17(7):A513. https://doi.org/10.1016/j.jval. 2014.08.1580.
51. Mejdahl CT, Schougaard LMV, Hjollund NH, Riiskjær E, Thorne S, Lomborg K. PRO-based follow-up as a means of self-management support-an interpretive description of the patient perspective. J Patient Rep Outcomes. 2018;2:38. https://doi.org/10.1186/s41687-018-0067-0.

52. Oerlemans S, Arts LP, Horevoorts NJ, van de Poll-Franse LV. "Am I normal?" the wishes of patients with lymphoma to compare their patient-reported outcomes with those of their peers. J Med Internet Res. 2017;19(8):e288. https:// doi.org/10.2196/jmir.7079.

Publisher's Note Springer Nature remains neutral with regard to jurisdictional claims in published maps and institutional affiliations.

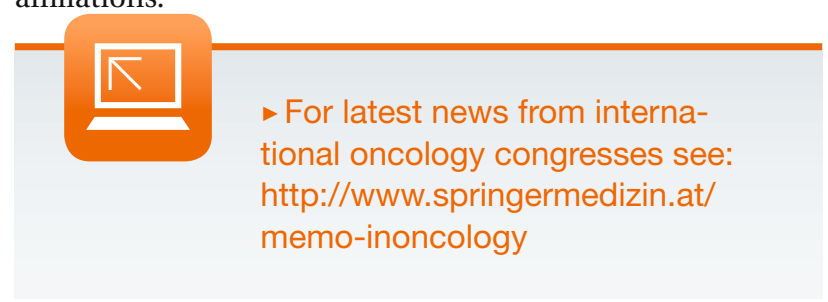

